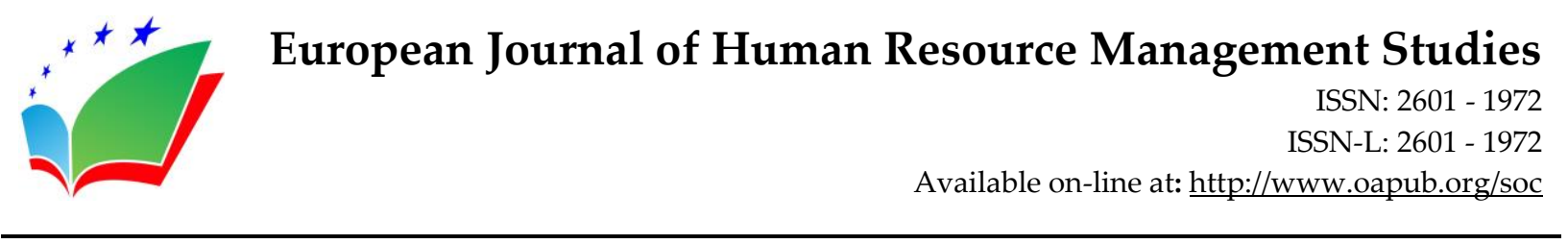

\title{
HUMAN RESOURCES DEVELOPMENT IN VIETNAM: CURRENT SITUATION AND SOLUTIONS
}

\author{
Pham Thi Kien ${ }^{\mathrm{i}}$ \\ PhD, University of Economics Ho Chi Minh City, \\ Ho Chi Minh City, Vietnam \\ orcid.org/0000-0001-8024-8679
}

\begin{abstract}
:
There is a cause \& effect relationship between human resources, capital, natural resources, technical infrastructure, science \& technology, etc. However, human resources are considered the endogenous factor that dominates other resources as well as the process of socioeconomic development of each country. Compared to other resources, human resources, in which intellectual and grey matter are prominent characteristics, have the outstanding advantage of not being exhausted if they can be fostered, exploited and used properly; while other resources, no matter how much, are limited and can only prove their usefulness by being combined with human resources effectively. Human resources are the factor that decides the exploitation, use, protection and regeneration of other resources; in which, high-quality human resources determine the socioeconomic growth and development of each country.
\end{abstract}

JEL: J24; O15

Keywords: development, human resources, Vietnam

\section{Introduction}

The term "human resource" has long been used in practice and actually should be understood as a type of resource found in human. This resource is human capabilities as individuals as well as people in general to carry out activities that are useful to society and each of them. It is implied that this is a potential resource that can be used to create competitive advantage for those who use it. This resource can only transform into real values when being exploited and used to create products and services (or added values) for the society and the individuals that own it. The concept of human resource is used at different levels, and its connotation includes different contents and elements depending on each level.

i Correspondence: email kienpt@ueh.edu.vn 
At individual level, human resources include the potentials of each particular person to carry out activities that benefit the society. Therefore, at this level, it is the individual capabilities of each person. These capabilities are the combination of knowledge, skills, attitudes and health that each person can use in the activities they perform. Because activities of each individual are often included in the overall social activities, when considering human resources, the focus is often on human capabilities in performing "social activities" or "activities that serve the society". However, since each person is also a social entity, the activities that serve themselves must also be considered social activities (at individual level), and the capabilities to perform such activities must also be considered as part of the human resources contained in a particular person.

At organization level, human resources are the sum of capabilities of the individuals constituting the organization and how they are combined to carry out activities of the organization, which are usually determined by four factors: quantity, quality, structure of the labor force and mechanism for mobilizing and using the labor force in that organization. These resources can be expanded by the mobilization of external human resources (through outsourcing), a trend which has been on the rise in recent years.

At nation level (and more broadly, the society in general), human resources consist of the entire labor force that the society can exploit and use at a time or in a given period of time, which is gathered in the statistics indicator of "number of people with work capability". Some experts use the "number of people with work capability and at working age" to determine the "quantity" of human resources, with the implication that these resources must be acknowledged by law (those who are able to work but under the legal working age cannot be used) (ii).

Human resources exist as potentials, which can be either known or unknown. Moreover, as a resource, human resources have objective characteristics and attributes (results formed/created under objective conditions), as well as completely defined "use value" or "use", and can (or cannot) meet requirements of exploitation and use of specific subjects at each specific time. Once mobilized, these capabilities become inputs for the activities they are mobilized for (among other factors such as monetary capital, natural resources, technologies). The exploitation and use of human resources depend on 4 basic factors: 1) human resources themselves (quantity and quality), 2) perception of human potential, 3) purpose/orientation of how to use it and 4) method of using this resource.

Human resources are an active element of social activities, originating from the active role of human in the society. However, the active role of human in particular and of human resources in general does not mean that they can arbitrarily dominate the development of society and of processes where specific individuals (as well as human resources in general) are used as inputs (resources).

Like all other countries, human resources in Vietnam have been exploited and used by economic-political-social organizations or by some individuals themselves

\footnotetext{
ii The International Labor Organization (ILO), which has always opposed the abuse of child labor and illegal and unethical use of labor, often defines the concept of human resource in this sense.
} 
(independent, self-employed workers). The exploitation and use of human resources in general as well as specific individuals in particular in each specific process and social activity must comply and be consistent with objective rules governing such processes and activities.

\section{Current situation}

In recent years, there have been many studies and assessments on the current situation of human resources in Vietnam. In addition to advantages and strengths, such as a large quantity of young people with initially above-average educational background, diligence and creativity, human resources in Vietnam also have essential disadvantages and shortcomings. The main limits and shortcomings of human resources in Vietnam are:

- Low professional and technical qualifications. Statistics as well as survey results in many studies show that the number of trained labor in Vietnam is low compared to the region and the world. In 2018, although statistics recorded that $41.1 \%$ of total number of employees working in economic sectors are trained, the percentage of trained workers to whom certificates are issued is too low $(21.9 \%$ in 2018), the proportion of workers without technical expertise is high and the structure of labor qualifications is still inappropriate ${ }^{\mathrm{iii}}$. In addition to qualifications, Vietnamese labor force is also weak in terms of soft skills, which leads to limited coordination and cooperation and makes it difficult to assign them to production lines and jobs that require labor division and close coordination. Another point that has been discussed quite a lot recently is the limitation of a large part of Vietnamese workers in terms of enthusiasm, initiative, sense of responsibility, sense of discipline and professional ethics, etc.

- Inappropriate distribution of labor. The distribution is inappropriate in terms of space (labors, especially trained ones with high qualifications are overly concentrated in large cities), economic sector (workers are rapidly increasing and concentrating in service industry, while the number of workers in physical manufacturing industries, especially those with heavy work and low income, tends to quickly decline), and profession (technical occupations decrease while service and management occupations rapidly increase).

- Low labor productivity. This is a consequence of limitation in qualifications of the labor force and the level of using labor in Vietnam. Generally, in the 2008-2017 period, labor productivity by purchasing power parity in 2011 (PPP 2011) of Vietnam increased by an average of $4 \%$ /year, higher than Singapore $(0.9 \%)$, Malaysia (1.1\%), Thailand (2.6\%), Philippines (3.3\%) and Indonesia (3.4\%). However, the current productivity of Vietnam is still very low compared to other countries in the region. Specifically, according to PPP 2011, labor productivity of Vietnam in 2017 was 10,232 USD, equal to 7.2\% of Singapore; 18.4\% of Malaysia,

\footnotetext{
iii https://dantri.com.vn/lao-dong-viec-lam/ty-le-lao-dong-qua-dao-tao-o-viet-nam-con-thap20200617081909172.htm
} 
$36.2 \%$ of Thailand, $43 \%$ of Indonesia and $55 \%$ of Philippines ${ }^{\text {iv }}$. Notably, the difference in labor productivity between Vietnam and other countries continues to increase.

- Contribution of the labor force to GDP growth is low and tends to decrease. In 2015 , this only contributed to $19.8 \%$ of national GDP growth (while the factor of capital accounts for $70.66 \%$ ). Compared to the average contribution of $23.74 \%$ of this factor in 2000- 2005 period, the number decreased by $16.6 \%$ in $2015^{\text {(v). }}$

\section{Causes}

- Inadequate awareness of nature and characteristics of human resources: Currently, there is a common misconception of identifying occupation structure with labor structure based on the economic sectors that employ them, and identifying structure by educational background with structure by qualifications. This misconception leads to mistakes in making policies and plans to develop human resources as well as in recruiting, evaluating, developing and paying remuneration to the national labor force as well as in every region and at every enterprise. Recently, in many projects using foreign capital (mainly ODA), "experience" is used as an element of quality (qualifications and capabilities) of employees. However, ambiguous definition or incorrect explanation and application of this concept lead to the selection of wrong people and the elimination of quite a lot of people who are really suitable for the job, limiting their employment opportunities and adversely affecting the development of the respective team of experts (especially domestic experts). On the other hand, extreme notions or prejudices have falsely judged and assessed the potential of human resources (overemphasizing or underestimating quality of the labor force, especially experts in the country), making them not to be used adequately, thereby having negative impacts on the development of human resources in Vietnam.

- Awareness of and practical response to conditions for exploitation and use of human resources are not sufficient and consistent: Although human resources are considered an element of the labor process and need to be balanced with other material resources, in fact, people often don't have enough other production factors to work effectively. Actually, this perception is not new and has been talked about quite a lot, especially when it comes to "synchronization" in production and business activities as well as in other social activities. The problem is that it is not thoroughly, systematically and consistently observed throughout the process of using labor (relating to initial investment, addition and modernization of work conditions throughout the employment process of each person).

- The needs for human resources are not clearly specified: Human resources can only be formed in a decades-long process. The exploitation and use of human

\footnotetext{
iv https://baodautu.vn/nang-suat-lao-dong-cua-viet-nam-rat-thap-d105073.html

v Do Van Thanh, J. FittzGerald, Do Van Lam: Assessment of Vietnam's potential yield in the 2011-2015 period. Hanoi, 12. 2011.
} 
resources in an individual also last for decades. The adjustment and addition of elements constituting the capability of each worker (and the workforce in general) are often difficult and time-consuming. This process is influenced by many different factors, individuals and organizations, some of which may be single, non-repeating opportunities. This process will have a lasting impact not only on the knowledge, skills and attitude of each individual employee, but also on their motivation to work. Human resource development that does not adhere to practical needs not only wastes social wealth and expenses of individual and corporate employers, but also leads to long-term and profound adverse impacts on the entire society, organizations and individuals.

\section{Solutions}

First, assess and clearly identify the demand for human resources and requirements for the training and development of human resources in Vietnam in the next decade. Assessment and clear identification of demand for human resources is the prerequisite and the foundation for training and developing human resources in an appropriate and effective manner, as well as for identifying redundant workforce and solutions for their employment (there are also specific requirements for this group of workers) at the same time. This not only helps institutions in charge of training and developing human resources to prepare their work plans, but also helps functional agencies of the State to develop more integrated strategies to exploit this resource. Therefore, the assessment of the demand for human resources should be led by the State, then the results are announced to the public for common use. Led by the State, specific assessments should be conducted by research agencies and organizations according to the State's orders.

The assessment and identification of demand for human resources should be carried out systematically (based on the social needs of each industry, each locality and each socio-economic organization). Different agencies and organizations can be mobilized to simultaneously participate in this work to ensure the accuracy of the forecast results. In addition, to increase the accuracy of forecast, it is necessary to apply a regular forecasting method. After conducting overall assessments (about every 5 years), annual evaluation and systematic review and adjustment of information on human resources are needed. Career-related demands of the workforce need to be paid more attention.

Second, reform and upgrade the system of training and developing human resources. Experts of the World Bank recommend East Asian countries (including Vietnam) to reform their education and training system and develop human resources in 3 areas:

- Financial mechanism for human resource training system

- Autonomy of training institutions

- Mechanism to bind the training system to practice, especially the private sector. These recommendations are fully adapted to the development of education and training system in order to develop human resources in Vietnam. 
Third, promote career development orientation and guide workers to different occupational tracks. These are orientation activities for individuals to evaluate their strengths in order to choose the direction to develop their own professional capabilities and career. The process of forming foundation knowledge and skills for the entire development of each individual plays a crucial role throughout each person's life, and also has impacts on the entire "cycle of human resource renovation" in each individual. In order to avoid detrimental impacts from the spontaneous participation of workers in the labor market right from the stage of preparation and spontaneous development of human resources, it is necessary to increase career orientation and guide workers to different occupational tracks. These activities help each individual to select a career that suits their own capabilities, qualities and orientation, and at the same time meet requirements regarding the labor force of the society. These can be considered a content of training and development of human resources. However, considering the extent of their impact and importance in the next period, they should be considered as an independent group of solutions to which attention must be paid for implementation. It not only means to guide each potential worker, but also is significant to institutions in charge of training, fostering and developing human resources as well as the entire economy and society.

Fourth, strengthen the capability of domestic experts through projects of capability building and technology transfer from overseas. To do this, it is first and foremost the responsibility of project management boards and governing bodies of these projects. As the entity to directly use (and usually recruit), project management boards need to propose specific additional requirements for international experts on the transfer of knowledge, technologies and methods of performing tasks to domestic experts and officials of agencies that benefit from results of their work. In case a time schedule can be arranged, it is necessary to determine their responsibilities in holding discussions and seminars to exchange experience with Vietnamese officials in the same fields, participating in scientific seminars on professional issues and presenting reports (methods used and results obtained) there.

Fifth, complete the work of creating motivation to promote the capability and efficiency of using labor in order to promote the self-training of workers.

Lifelong learning, self-training, self-improvement, etc. are sustainable activities that have great impacts on the promotion of individual capabilities and potentials of human resources within organizations and the entire society. This can only be achieved if the workers themselves have internal motivation to work and feel attached to their position and the organization they are working for. For long, creating motivation for workers to actively work with high efficiency has been studied quite a lot. Employers have also paid attention to this and many have done it well. In order to effectively and sustainably motivate workers, research is needed to identify motivation-generating factors and their impacts to create motivation. In fact, motivation-generating factors for workers also vary between groups of people and change over time. Some other factors are also mentioned at a rather limited level, such as opportunities to learn and improve professional qualifications, to be autonomous at work, to be respected in the work environment, etc. 
However, creating motivation for workers and even for employers to actively and constantly improve their qualifications and develop themselves is yet to attract attention. This requires efforts and supports from employees, employers and State management agencies.

\section{Conflict of Interest Statement}

The author declares no conflicts of interests.

\section{About the Author}

Pham Thi Kien is a lecturer of School of Social Science, University of Economics Ho Chi Minh City, Ho Chi Minh City, Vietnam. She studies philosophy, human philosophy, human resources, culture, logic and politics. She obtained her PhD in VNUHCMUniversity of Social Sciences and Humanities in 2017, with specialization Dialectical materialism and historical materialism.

\section{References}

1. Pham Thi Hanh, https://tapchicongsan.org.vn/web/guest/van hoa xa hoi/2018/815949/phat-trien\%2C-nang-cao-chat-luong-nguon-nhan-luc-trong-boicanh-cuoc-cach-mang-cong-nghiep-lan-thu-tu.aspx

2. Alvin Toffler: Power: Ups and Downs, Theory and Information Publishing House, Hanoi, 1992, p. 41

3. Ho Chi Minh: Full collection, National Politics Publishing House, Hanoi, 2011, vol.11, p. 528

4. Ho Chi Minh : National Politics Publishing House, Hanoi, 2011, vol.15, p. 616

5. Ho Chi Minh : National Politics Publishing House, Hanoi, 2011, vol.15, p. 622

6. Documents of the $5^{\text {th }}$ session of the $8^{\text {th }}$ Central Executive Committee, National Politics Publishing House, 1998, p. 93

7. Documents of the $11^{\text {th }}$ National Congress, National Politics Publishing House, 2011, p. 41.

8. Documents of the $11^{\text {th }}$ National Congress, National Politics Publishing House, 2011, p. 130

9. Documents of the $12^{\text {th }}$ National Congress, Central Office of the Party, Hanoi, 2016, p. 90

10. Documents of the $12^{\text {th }}$ National Congress, National Politics Publishing House, 2011, p. 116 
Creative Commons licensing terms

Authors will retain copyright to their published articles agreeing that a Creative Commons Attribution 4.0 International License (CC BY 4.0) terms will be applied to their work. Under the terms of this license, no permission is required from the author(s) or publisher for members of the community to copy, distribute, transmit or adapt the article content, providing a proper, prominent and unambiguous attribution to the authors in a manner that makes clear that the materials are being reused under permission of a Creative Commons License. Views, opinions and conclusions expressed in this research article are views, opinions and conclusions of the author(s).Open Access Publishing Group and European Journal of Management and Marketing Studies shall not be responsible or answerable for any loss, damage or liability caused in relation to/arising out of conflict of interests, copyright violations and inappropriate or inaccurate use of any kind content related or integrated on the research work. All the published works are meeting the Open Access Publishing requirements and can be freely accessed, shared, modified, distributed and used in educational, commercial and non-commercial purposes under a Creative Commons Attribution 4.0 International License (CC BY 4.0). 